\title{
A ordem dos fatores não altera o resultado?
}

\author{
Does the order of the factors change the result?
}

¿El orden de los factores cambia el resultado?

\author{
Ester Mendonça Ramos ${ }^{2}$ \\ Maria Auxiliadora Bueno Andrade Megid ${ }^{3}$
}

\begin{abstract}
Resumo: O artigo apresenta uma investigação que utilizou jogos matemáticos propostos pelo Pacto Nacional pela Alfabetização na Idade Certa (PNAIC). O objetivo foi analisar episódios relacionados ao campo multiplicativo, referentes ao jogo "A bota de muitas léguas". Apresentam-se reflexões da pesquisadora, alusivas às experiências proporcionadas pelo uso do jogo. Utilizaram-se diário de campo, fotografias, áudio e videogravações. Como resultado, as análises sobre a abordagem do campo multiplicativo indicam a potencialidade do uso de práticas pedagógicas amparadas em jogos para ampliar a compreensão do referido conteúdo pelas crianças, a partir da mediação da professora, o que contribuiu para a resolução da situaçãoproblema apresentada. Ainda, verificou-se a importância da identificação do multiplicador e do multiplicando, apesar de a comutatividade, presente na multiplicação, não alterar o resultado da operação.
\end{abstract}

Palavras-chave: Alfabetização matemática. Números e operações. PNAIC.

Abstract: The article presents an investigation that used mathematical games proposed by the National Pact of Literacy at the Right Age (PNAIC). The objective was to analyze episodes related to the multiplicative field, referring to the game "A boot of many leagues". The researcher's reflections are presented, alluding to the experiences provided by the use of the game. Field diaries, photographs, audio and video recordings were used. As a result, the analyzes on the approach of the multiplicative field indicate the potential of the use of pedagogical practices supported by games to expand the understanding of the referred content by the children, through the mediation of the teacher, which contributed to the resolution of the problem situation presented. Still, it was verified the importance of identifying the multiplier and the multiplicand, although the commutativity, present in the multiplication, does not change the result of the operation.

Keywords: Mathematical literacy. Numbers and operations. PNAIC.

Resumen: El artículo presenta una investigación que utilizó juegos matemáticos propuestos por el Pacto Nacional por la Alfabetización en la Edad Adecuada (PNAIC). El objetivo era analizar episodios relacionados con el campo multiplicativo, refiriéndose al juego "Un arranque de muchas ligas". Se presentan las reflexiones del investigador, aludiendo a las experiencias proporcionadas por el uso del juego. Se utilizaron diarios de campo, fotografías, grabaciones de audio y video. Como resultado, los análisis sobre el enfoque del campo multiplicativo indican el potencial del uso de prácticas pedagógicas apoyadas por juegos para expandir la comprensión del contenido referido por parte de los niños, a través de la mediación del maestro, que contribuyó a la resolución de la situación problemática presentada. Aún así, se verificó la importancia de identificar el multiplicador y el multiplicando, aunque la conmutatividad, presente en la multiplicación, no cambia el resultado de la operación.

Palabras clave: Alfabetización matemática. Números y operaciones. PNAIC.

\footnotetext{
${ }^{1}$ Submetido em: 17 mar. 2020 - Aceito em: 21 jul. 2020 - Publicado em: 15 jan. 2021

${ }^{2}$ Secretaria Municipal de Educação de Campinas (SME - Campinas) - E-mail: ester_mendonca@hotmail.com

${ }^{3}$ Pontifícia Universidade Católica de Campinas (PUC-Campinas) - E-mail: doramegid@gmail.com
} 


\section{Introdução}

Este artigo refere-se a um recorte da pesquisa de mestrado, na qual a professorapesquisadora investigou a própria prática na sala de aula em que atuava durante a pesquisa, em uma escola municipal da cidade de Campinas, São Paulo, em 2018. O objetivo geral do referido estudo foi investigar quais os saberes desenvolvidos pela professora-pesquisadora, a partir da utilização de jogos para a aprendizagem de números e operações com crianças de $3^{\circ}$ ano do Ensino Fundamental, buscando analisar as ações educativas que contribuíram para esse processo e as transformações na prática docente.

Os jogos foram escolhidos pelo fato de a professora-pesquisadora ter procurado estudar recursos que pudessem despertar o interesse e a motivação dos alunos, considerando que "o uso de jogos implica uma mudança significativa nos processos de ensinoaprendizagem, que permite alterar o modelo tradicional de ensino, o qual muitas vezes tem no livro e em exercícios padronizados seu principal recurso" (SMOLE; DINIZ; CÂNDIDO, 2007, p. 11).

A professora-pesquisadora é participante do Grupo de Estudos Professores Matematizando nos Anos Iniciais - GEProMAI -, que se reúne semanalmente na Pontifícia Universidade Católica de Campinas (PUC-Campinas). Os estudos nesse grupo motivaram a investigação do tema, bem como a participação da professora-pesquisadora no processo formativo do "Pacto Nacional pela Alfabetização na Idade Certa" (PNAIC), em 2014 (BRASIL, 2014a).

Tal participação trouxe contribuições significativas para a formação e a atuação da professora-pesquisadora, que no início da sua carreira como docente sentia insegurança ao ministrar as aulas de matemática para suas turmas dos anos iniciais do Ensino Fundamental. Não tinha domínio do conteúdo a ser ensinado e, menos ainda, de estratégias para ensiná-lo. Apoiava-se em lembranças de como havia aprendido na escola, nos livros didáticos existentes nas unidades de ensino onde atuava e na troca de experiências com os colegas de trabalho.

Com efeito, Megid (2015) destaca os desafios vividos pelos professores que ensinam matemática nos anos iniciais, os mesmos com os quais a professora-pesquisadora se deparou: a insegurança, a reprodução de ações vivenciadas na infância e, ainda, a falta de tempo para planejamento e estudos.

O PNAIC foi importante para a formação da professora-pesquisadora, permitindo-lhe desbravar novos recursos e entender, por outros caminhos, determinados conceitos matemáticos. Com a nova formação, começou a se preocupar mais com o processo de ensino e aprendizagem dos alunos e com a forma de ensinar. Por fim, o programa proporcionou-lhe momentos de reflexão e também de troca de experiências entre os professores.

Seu processo formativo professora-pesquisadora desde o início de sua carreira docente, sua participação no PNAIC e no GEProMAI, sua busca por estratégias para despertar o interesse dos alunos e a melhoria do trabalho docente, foram as motivações que a levaram a pesquisar a própria prática. 
A imagem na Figura 1 foi produzida pela professora-pesquisadora para indicar os principais aspectos relacionados ao desenvolvimento da pesquisa.

Figura 1. Aspectos relacionados ao desenvolvimento da pesquisa

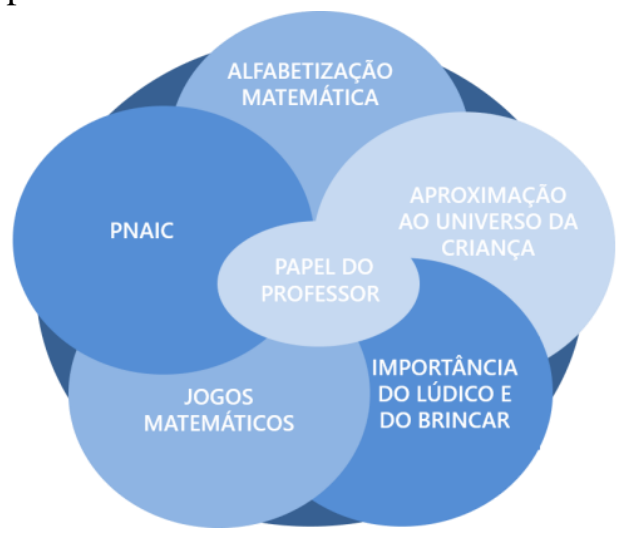

Fonte: Elaboração das autoras.

A alfabetização matemática no PNAIC está ancorada na perspectiva do letramento matemático, considerando os aspectos sociais da matemática, que vão além do domínio de códigos e técnicas operatórias. Nesta perspectiva, Passos e Nacarato (2018, p. 123) consideram o letramento matemático como "uma educação Matemática que valoriza os saberes dos estudantes e os ajuda a compreender os modos como a nossa sociedade organiza suas experiências com apoio da Matemática, promovendo compreensão e leitura de mundo".

Assim, para o ensino da matemática, o programa indica a aproximação com o universo da criança, enfatizando a importância do lúdico e do brincar. Nesse caminho, apresenta como uma das possibilidades de trabalho o uso dos jogos matemáticos, os quais, segundo Nacarato, Mengali e Passos (2009) estimulam a participação ativa dos alunos na construção do conhecimento e na construção de significados de conceitos matemáticos. $\mathrm{O}$ PNAIC ainda indica a importância do papel do professor para o processo de alfabetização matemática, como ressaltam Nacarato, Mengali e Passos (2009), que atribuem ao professor o papel principal para a constituição de um ambiente que promova a aprendizagem, principalmente, no que se refere à escolha das atividades e do método a ser utilizado. Neste caso, o caminho escolhido pela professora-pesquisadora para desenvolver a investigação foi o uso de jogos, o que parece adequado ao trabalho com alunos dos anos iniciais, etapa fundamental para a compreensão de diversos conceitos básicos necessários para alcançar outros mais complexos, muito embora o ensino da matemática, muitas vezes, ainda seja pautado na memorização e na cópia de modelos, estimulando o aluno a apenas encontrar respostas certas, sem compreender os conceitos envolvidos.

Com o objetivo de promover significação no processo de ensino e aprendizagem da matemática, foram escolhidos para esta investigação dois jogos propostos pelo PNAIC, do eixo números e operações. Os jogos selecionados, segundo Muniz (2014), devem ser propostos pelo professor e utilizados como atividade didática, seguindo as regras previamente ensinadas. "O professor, neste caso, é criador, prescritor e controlador da atividade lúdica" 
(MUNIZ, 2014, p. 129). Nessa perspectiva, a pesquisa também se vê ancorada em Grando (1995, p. 52), que conceitua como jogos pedagógicos aqueles que "possuem seu valor pedagógico, ou seja, que podem ser utilizados durante o processo de ensino e aprendizagem".

Por conseguinte, os jogos utilizados nesta pesquisa possuem intencionalidade pedagógica e visam ao aprendizado de conceitos matemáticos, objetivando a aprendizagem de conceitos importantes no campo dos números e das operações, entre eles, o valor posicional e o campo multiplicativo.

Este artigo tem o objetivo de apresentar as análises de alguns episódios desta pesquisa, que se referem ao jogo "A bota de muitas léguas". A proposta se voltou ao trabalho com situações-problema do campo multiplicativo e proporcionou revelar as reflexões da professora-pesquisadora a partir do uso desse jogo. Passemos à apresentação, portanto.

Inicialmente, diante do eixo "números e operações", importa caracterizar o sentido de número como "algo impreciso, pessoal e personalizado, que está relacionado com as ideias que cada um foi estabelecendo sobre os números e as operações e que nem sempre é fácil de descrever" (CEBOLA, 2002, p. 226). Na mesma direção, Van de Walle (2009, p. 148) destaca que a evolução do senso numérico é algo constante, "se desenvolve quando os estudantes compreendem o tamanho dos números, desenvolvem múltiplos modos de pensar sobre e representar números, usam números como referentes e desenvolvem percepções precisas sobre os efeitos das operações sobre os números”. Ele é ampliado, quando as crianças começam a "usar números em operações, construir uma compreensão do valor posicional e elaborar métodos flexíveis para calcular e fazer estimativas envolvendo grandes números" (VAN DE WALLE, 2009, p. 148).

O desenvolvimento do sentido numérico possibilita a compreensão do Sistema de Numeração Decimal, sendo suas principais características: "a base decimal, a notação posicional e dez signos que possibilitam representar qualquer número", do 1 ao 9 e o zero, que se refere ao "vazio ou espaço em branco" (TOLEDO; TOLEDO, 2009, p. 62).

É preciso ainda destacar a diferenciação entre o raciocínio aditivo e o raciocínio multiplicativo, como indicado por Nunes et al. (2009, p. 84): o raciocínio aditivo é a relação parte-todo. Quando se pretende "saber o valor do todo somamos as partes; se queremos saber de uma parte, subtraímos a outra parte do todo; se queremos comparar duas quantidades, analisamos que parte da maior quantidade sobra se retirarmos dela uma quantia equivalente à outra parte". Tais práticas envolvem diversas ações, como juntar, separar e fazer correspondências, apontadas pelos autores como esquemas de ação associados ao campo aditivo.

A ele relaciona-se o raciocínio multiplicativo, assim definido por Nunes et al. (2009, p. 85): "é a existência de uma relação fixa entre duas variáveis (ou duas grandezas ou quantidades). Qualquer situação multiplicativa envolve duas quantidades em relação constante entre si". Os autores ponderam que as crianças, desde cedo, realizam a multiplicação de maneira prática, utilizando o esquema de ação de correspondência um-amuitos, empregando o raciocínio aditivo e o esquema da distribuição equitativa nos problemas que envolvem divisão. 
Apresentados os princípios, cabe indicar o método utilizado na investigação e suas características.

\section{Caminho percorrido}

A investigação configurou-se em uma pesquisa de natureza interventiva e da própria prática, pois a pesquisadora assumiu um duplo papel: professora e pesquisadora. Teixeira e Megid Neto (2017, p. 107) apontam a pesquisa da própria prática como pertencente a um rol de estudos de natureza interventiva e afirmam que "as pesquisas nesta área estão envolvidas em processos de compreensão e melhoria do trabalho docente, começando pela reflexão sobre a própria prática e experiências profissionais".

Lima e Nacarato (2009) indicam dois movimentos que configuram a pesquisa da própria prática: o primeiro refere-se ao professor que, voluntariamente, participa de grupos colaborativos, discutindo problemas que surgem em sua sala de aula; o outro refere-se ao professor que ingressa em um programa de pós-graduação e investiga a sua própria prática. Os dois movimentos foram vivenciados pela professora-pesquisadora e contribuíram para o processo de reflexão sobre suas ações.

Ponte (2002, p. 3) apresenta três justificativas para se realizar a pesquisa da própria prática, nas quais este estudo se ancora. A primeira refere-se ao professor, que nesse tipo de pesquisa se torna protagonista do desenvolvimento curricular e profissional. A segunda diz respeito à capacidade da investigação de potencializar o desenvolvimento profissional do professor e de agir na cultura escolar, com possibilidades de transformá-la. A terceira justificativa está relacionada ao fato de que a pesquisa da prática contribui com elementos que proporcionam maior entendimento dos problemas educacionais e da cultura profissional. Segundo o autor, esse tipo de pesquisa envolve situações reais, da prática docente, com problemas normalmente vividos pelo professor e pesquisador. Tem o objetivo de intervir e transformar, compreendendo, preliminarmente, os problemas de investigação e, em um segundo momento, ativando estratégias de ação mais adequadas.

Uma vez caracterizada a natureza deste estudo, passamos a considerar os instrumentos de pesquisa: será aqui explicitada a utilização de um jogo proposto no material de formação do PNAIC - "A bota de muitas léguas" -, com a descrição das observações, os relatos orais e escritos, as problematizações propostas pela professora-pesquisadora antes, durante e após a utilização dos jogos. Para o registro, foram utilizados diário de campo, fotografias, áudio e videogravações. A pesquisa efetuou o seguinte percurso: 
Figura 2. Percurso da pesquisa

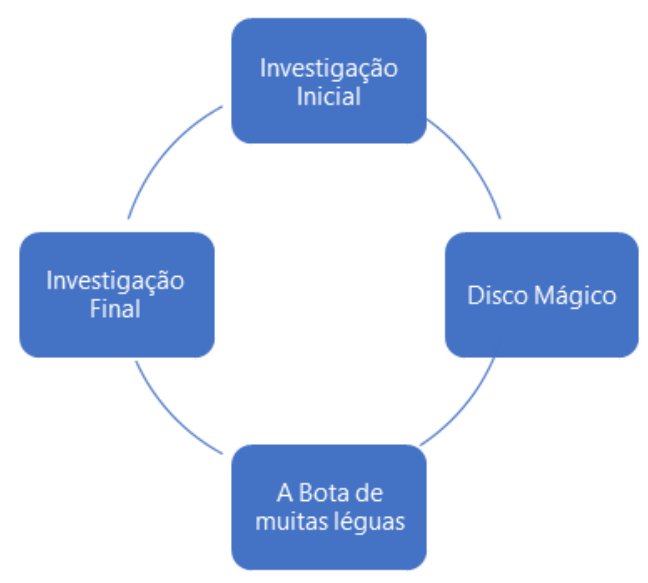

Fonte: Elaboração das autoras.

As etapas de investigação inicial e final se constituíram por um diálogo da professorapesquisadora com a turma e pela escrita dos alunos a respeito do que pensavam sobre as aulas de matemática, antes e depois do uso de jogos, configurando momentos que auxiliaram no processo de reflexão sobre a prática da professora.

O jogo foi realizado em três momentos distintos, conforme indicado pelo PNAIC, no "Caderno de jogos na alfabetização matemática" (BRASIL, 2014b). O primeiro ocupou-se com a apresentação do jogo, dos materiais utilizados e das regras e com a divisão das equipes. O segundo tratou da aplicação dos jogos, propriamente dita. O terceiro abrangeu momentos de socialização, impressões, reflexões sobre o que se aprendeu em matemática e problematizações orais e escritas.

As experiências com o jogo "A bota de muitas léguas" aqui relatadas tinham como objetivo de aprendizagem "elaborar, interpretar e resolver situações-problemas do campo multiplicativo (multiplicação e divisão), utilizando e comunicando suas estratégias pessoais por meio de diferentes linguagens e explorando os diferentes significados" (BRASIL, 2014c, p. 33). Esse documento afirma, ainda, que esse jogo visa "desenvolver a ideia de multiplicação e divisão ao calcular a quantidade de pulos que a "bota" dará; utilizar o zero como referencial de ponto de partida" (BRASIL, 2014c, p. 33).

Na prática com o jogo, são apresentadas duas variáveis necessárias para a realização da multiplicação: a quantidade de pulos e o tamanho deles. Para desenvolver as atividades com esse jogo, o "Caderno de jogos na alfabetização matemática" do PNAIC (BRASIL, 2014c) indica que o professor deve desenhar a reta graduada no chão - usar uma faixa de papel graduada - com as marcações de 0 a 25 . O caderno propõe o uso de fichas azuis e amarelas, de 0 a 5 , sendo uma cor para o tamanho do pulo e outra cor para a quantidade de pulos. O aluno sorteia uma ficha de cada cor e calcula em qual número chegará na reta. Em sua prática, a professora-pesquisadora realizou uma adaptação: ao invés das fichas coloridas, utilizou dois dados, um para cada objetivo, ou seja, um para o tamanho do pulo e outro para a quantidade de pulos a serem dados pelo jogador. 
A partir da apresentação desses episódios, este artigo visa apresentar as reflexões relacionadas ao campo multiplicativo, realizadas pela professora-pesquisadora sobre o ensino da matemática nos anos iniciais, envolvendo as ideias de multiplicação e divisão. Entretanto, embora seja uma pesquisa da própria prática, que contou com os processos reflexivos da professora-pesquisadora durante todo o desenvolvimento do estudo, foram registradas, também, ações realizadas em parceria com a orientadora, também autora deste artigo.

A pesquisa foi aprovada pelo Comitê de Ética da Pontifícia Universidade Católica de Campinas, com o Parecer de número 2.907.681. Também contou com a autorização dos alunos e de seus responsáveis, pelas assinaturas dos termos de consentimento livre e esclarecido e de assentimento.

\section{O percurso do jogo}

Este relato permitirá ao leitor acompanhar jogadas das crianças ao longo da atividade e, para preservar-lhes o anonimato, elas foram identificadas pela letra $\mathrm{C}$, acompanhada de um número, ou seja, a inscrição C1 será usada para indicar sempre a mesma criança, o mesmo ocorrendo com todas as outras. A letra P é utilizada para indicar as inserções da professorapesquisadora.

A professora apresentou o jogo aos alunos e levou-os à quadra, onde havia inscrito uma reta com marcações de 1 a 25 - cada uma delas corresponderia a um pulo das crianças. Foram selecionadas algumas jogadas para serem apresentadas neste artigo, aquelas úteis para a análise do trabalho com o princípio multiplicativo.

Inicialmente, destacamos a jogada da aluna C26. O dado referente à quantidade caiu no número 3 e, em relação ao tamanho, no número 4:

C12: Primeiro, ela vai ter que cair no três.

P: $O$ tamanho do pulo é quatro.

C12: Então, do zero até o 3.

A professora foi até a reta, demonstrou qual era a distância de tamanho 4 e seguiu andando e somando:

P: Do zero até o 1, temos um; do 1 até o 2, temos mais um, que dá 2; do 2 até o 3, temos mais um, que dá 3; e do 3 até o 4, temos mais um, que dá 4. Então, você vai chegar no 4, e não no 3.

C12: Eu achava que caía no 3 porque o zero conta.

O aluno foi até a reta e contou o zero como se fosse o um.

C12: 1 (se referindo ao zero), 2 (se referindo ao 1), 3 (se referindo ao 2) e 4 (se referindo ao 3).

A professora voltou à reta e repetiu a explicação, somando de $1 \mathrm{em} \mathrm{1,} \mathrm{partindo} \mathrm{do} \mathrm{zero}$ $(1+1+1+1=4)$. Repetiu que o zero era o ponto de partida e mostrou que do zero até o 3 o 
total era 3, e não 4 .

C12: Ela vai fazer como a C16, mas [com] dois pulos a menos. Vai diminuir dois. P: [Para] a C16, foram cinco pulos de 4; e [para] a C26, são três pulos de 4. Em qual número ela vai chegar?

C22: 12.

P: $O$ C22 falou 12, será que está certo?

C7: Do zero até 12.

P: E por que 12 ?

C22: $0+4=4 ; 4+4=8 ; 8+4=12$.

P: Isso, três pulos de $4 ; 4+4+4=12$. Tem outra conta que vocês poderiam fazer? C22: De vezes?

P: Isso, pode ser $3 \times 4$, que é a mesma coisa que $4+4+4$, e o resultado é o mesmo.

A aluna iniciou os pulos, e os colegas auxiliaram na contagem, somando de $4 \mathrm{em} 4$ até chegar ao 12. Quando a aluna chegou ao 12, a professora-pesquisadora pediu que ela voltasse e fizesse o percurso, agora retornando de $4 \mathrm{em} \mathrm{4}$. Os outros alunos foram auxiliando na contagem $(12-4=8 ; 8-4=4 ; 4-4=0)$.

Neste diálogo, a discussão do zero como ponto de partida surgiu. O aluno C12 representou a quantidade 4, partindo do zero, mas atribuindo a ele "o 1". A representação da reta no chão auxiliou na intervenção e permitiu que a professora-pesquisadora demonstrasse para o aluno que o ponto de partida é o zero, diferentemente do que ele tinha feito. Enfatizou que, do zero ao 1, temos a distância "1" e, assim, sucessivamente. A reflexão sobre a dificuldade de algumas crianças compreenderem o significado do "zero" ficou mais evidente, para a professora-pesquisadora, nesta atividade. Refletir sobre as ações das crianças é prática nem sempre comum no cotidiano, sobretudo nas atividades relacionadas à Matemática. Por vezes, atribui-se o indicativo de acerto ou erro, sem buscar os caminhos, as intenções indicadas pelas crianças.

Os alunos não conseguiram estabelecer de maneira direta a relação de multiplicação entre os dois termos. Apenas C22, um aluno que apresenta bom rendimento na matemática, teve essa percepção. No primeiro momento, ele realizou a soma de parcelas iguais, ainda se referindo ao campo aditivo, utilizando a relação parte-todo, que se estabelece somando as partes para saber o todo, como encontrado em Nunes et al. (2009). Em seguida, ele mesmo explicou seu raciocínio, utilizando o campo multiplicativo. Para Nunes et al. (2009), essa é a relação entre duas variáveis - no caso, entre a quantidade de pulos e a distância percorrida.

Foi necessária a intervenção da professora-pesquisadora para que o aluno explicasse seu raciocínio e para que os demais começassem a compreender que era possível realizar uma multiplicação para calcular a distância percorrida, o que colaborou para a ampliação do campo numérico e do senso numérico.

Em seguida, C23 jogou, e foram sorteados cinco pulos de comprimento 5.

P: Cinco pulos de 5: em qual número da reta você vai chegar?

A aluna $\mathrm{C} 23$ não respondeu.

C3: $O$ resultado dela é 25 .

Educ. Perspect. | Viçosa, MG | v. 12 | p. 1-18 | e021003 | $2021 \mid$ eISSN 2178-8359 
P: A C3 falou que é 25; é isso? O que vocês acham? A equipe pode ajudar a C23.

A aluna C16 pediu para contar na reta e foi simulando os pulos que a C23 teria que fazer.

P: Vamos ajudá-la? [Com] o primeiro pulo, ela vai sair do zero e vai até onde?

Vários: 5!

P: E o próximo?

Vários: 10 !

P: E o terceiro pulo?

Vários: 15 !

P: E depois, o quarto pulo?

Vários: 20!

P: E o último pulo vai até o ...?

Vários: 25!

P: É isso mesmo, gente?

C3: $5 \times 5=25$.

P: Isso: Cinco grupos de 5 é a mesma coisa que 5 x 5. Vamos lá, C23!

Nessa jogada é perceptível que C3 compreendeu o conceito de multiplicação envolvido no jogo. Estabeleceu a relação entre as duas variáveis dos dois dados e realizou a multiplicação, diferentemente de C23, que apresentava dificuldades em matemática e ainda não conseguia compreender o campo multiplicativo. Com C23 foi necessário intervir, demonstrando os grupos de 5 e indicando que cinco grupos de 5, no campo aditivo, é como realizar 5 vezes o 5 .

Cebola (2002), ancorada em McIntosh et al. (1992), apresenta ideias que levam à caracterização do sentido do número básico, entre elas, o conhecimento e a destreza com os números, incluindo a compreensão das suas diversas representações, o que permite entender que $5+5+5+5+5$ é o mesmo que 5 x 5. C23, como ficou exemplificado linhas antes, ainda não havia compreendido a relação dessas representações, diferentemente de C3. A intervenção e o diálogo proporcionados pelo jogo, tanto com a professora-pesquisadora quanto com os colegas, permitiram a participação ativa de C23. Ela acompanhou a aluna e pediu para que somasse 5 a cada pulo. A aluna utilizou os dedos como apoio para a contagem.

De fato, os dedos são relevantes instrumentos de auxílio na contagem. Muniz, Santana, Magina e Freitas, no caderno de "Construção do Sistema de Numeração Decimal" (SND) do PNAIC (BRASIL, 2014b), indicam o apoio da contagem nos dedos como importante reforço na construção do número pela criança, uma base simbólica que é fundamental para esse processo, permitindo desenvolver estratégias de contagem e de resolução de cálculos. Megid (2010) destaca, ainda, o uso dos dedos como um “ábaco particular", que permite a elaboração de estratégias próprias pelas crianças.

Nessa jogada, o uso das mãos foi adotado por C23, aluna que ainda necessita de auxílio para compreender as operações básicas da matemática. Sendo assim, o uso dos dedos ainda era muito significativo para ela. Já C3, que demonstra uma maior compreensão, não utilizava mais os dedos como apoio.

Em seguida, o aluno C4, após arremessar os dados, precisou fazer dois pulos de tamanho 3 . 
P: C4, em qual número você vai terminar os seus pulos?

C4: No seis: $3+3$.

P: E qual outra conta você poderia fazer?

C28: De vezes.

$\mathrm{P}:$ De vezes? Como?

C21: 3 vezes 2.

P: São três pulos de 2 ou dois pulos de 3?

C4: São dois pulos de 3 .

P: Isso, são dois pulos de 3: $3+3$. E de vezes, como fica?

C4: 2 vezes 3.

P: Isso mesmo, são dois pulos de 3, e por isso, duas vezes o 3! Se fossem três pulos de 2, nós faríamos três vezes o 2 .

A fala do aluno C21 - "3 vezes 2" -, referindo-se ao resultado do cálculo relativo a dois pulos de tamanho 3, revelou que o aluno parece compreender a comutatividade no campo da multiplicação, conforme indicado por Nunes et al. (2009). Para três grupos de 2, temos o mesmo resultado de dois grupos de 3. Porém, o jogo contribui para o entendimento de que é necessário compreender a situação-problema para definir o multiplicador e o multiplicando. Esses termos não foram mencionados pela professora-pesquisadora, a qual interveio, no entanto, na tentativa de explicar que, naquele caso, apesar de o resultado ser o mesmo, a situação era diversa. Nessa jogada, são dois pulos de 3, ou seja, 2 x 3 ou $3+3$, que é diferente de três pulos de 2 , que seriam $2+2+2$ ou $3 \times 2$.

A professora não estava apenas considerando o resultado, mas tentando provocar a compreensão do processo que aquela situação proporcionava. Com a reta numérica, é possível demonstrar esse raciocínio de uma maneira prática. Não interessava apenas o resultado, que comprova a propriedade comutativa - a ordem dos fatores não altera o produto -, mas importava também compreender a multiplicação.

O próximo era $\mathrm{C} 30$. Os dados marcaram dois pulos de tamanho 3, como na jogada anterior. Facilmente, o aluno fez sua jogada. A professora-pesquisadora aproveitou o momento para realizar uma problematização do campo multiplicativo, mas referente ao processo de divisão. Quando o aluno pisou no número 6, perguntou:

P: $E$ se eu dividir 6 por 2 , quanto vai ficar?

C22: 3 .

A aluna $\mathrm{C} 3$ observou a reta e disse que era 3 .

P: Nós fizemos duas vezes 3, que deu 6. Agora, se eu dividir 6 por 2, vocês disseram que vai dar 3. C30, volta, então, dando dois pulos de 3 .

A professora-pesquisadora solicitou aos demais que observassem: o três era a metade de 6. Explicou que estavam fazendo a operação inversa: duas vezes o 3 resultava em 6, enquanto 6 dividido por 2 resultava em 3. Foi até a reta para demonstrar.

P: Vocês disseram que se eu dividir 6 por 2, cada parte vai ficar igual a 3.

Ficou parada no número 3 e pediu para eles observarem. Que verificassem que do 0 até 3, e do 3 até o 6, o tamanho era igual, ou seja, 3. Então, ela afirmou que encontraram a metade. Com isso, foi possível à professora-pesquisadora perceber que a divisão é um 
processo mais complexo de ser abordado e que uma das dificuldades das professoras de matemática dos anos iniciais, inclusive ela, consiste em explicar de maneira que os alunos entendam que a divisão é, entre outras alternativas, a operação inversa da multiplicação.

Nesse jogo, foi possível encontrar uma forma de demonstrar esse processo. O termo "metade" era conhecido pelos alunos. Ao pular na reta de forma inversa, a professorapesquisadora facilitou a explicação e confirmou a resposta de alguns alunos que haviam compreendido esse raciocínio; e foi possível retomar também a mesma ação com os demais alunos.

Com apoio em Grando (2000), é possível depreender que os desafios trazidos pelos jogos possibilitaram aos alunos desenvolver estratégias de resolução de problemas. Para além disso, a prática auxiliou a professora, que, no decorrer dos jogos, foi encontrando novas formas de problematizar conceitos de difícil compreensão para os alunos e, inicialmente, igualmente difíceis de serem explicados para ela.

Em uma outra jogada, novamente surgiu a propriedade comutativa e foi necessário intervir para que os alunos percebessem que, apesar de o resultado ser o mesmo, o cálculo deveria ser pensado de acordo com a situação apresentada. Nesse caso, o aluno teria que realizar dois pulos de tamanho 3.

C28: Podemos fazer três vezes 2 ou duas vezes 3, que dá 6 .

P: $O$ resultado é o mesmo, mas qual dessas duas contas eu vou usar neste caso? Foram dois pulos de 3 .

C18: Tem que ser duas vezes 3 .

P: Isso, eu posso fazer três vezes o 2?

Alguns: Não.

P: Isso, neste caso, não, porque são dois pulos de 3, e não três pulos de 2.

A importância da mediação na ação do jogo, como afirma Grando (2004), é claramente percebida nesse diálogo. Em seguida, C27 jogou e fez quatro pulos de tamanho 2.

$\mathrm{P}:[\mathrm{Com}]$ o primeiro pulo, onde você vai cair?

C27: No 2 .

A aluna foi andando até o número 2.

P: É um pulo de tamanho 2. Você tem que pular direto no 2.

C12 foi até a reta e demonstrou, caminhando até o 2.

A aluna foi somando de dois em dois e chegou até o 8.

P: Quantos pulos de 2 você fez?

C27: 4.

P: Qual o resultado?

C27: 8 .

P: Qual a conta que vocês vão registrar?

C12: $4 \times 2=8$.

P: Entendeu, C27? Vocêfez quatro pulos de $2(2+2+2+2$, que deu 8). Isso é a mesma coisa que fazer $4 \times 2=8$.

Nesse momento, mais uma vez, a professora-pesquisadora retomou a soma de parcelas iguais para explicar a multiplicação. A reta facilitou o entendimento do tamanho do pulo. A aluna utilizou a soma para realizar a contagem. Em seguida, C25 fez dois pulos de 
tamanho 5 .

P: Como [é] que a C25 vai fazer?

C31: É duas vezes 5, tipo isso?

C25: É um pulo de 5 e outro pulo de 5, que vai dar 10.

$\mathrm{P}$ : Isso, como o C31 falou, $2 \times 5$. Não esqueçam de registrar.

Essa jogada foi rápida, compreendida com facilidade pela aluna $\mathrm{C} 25$, e demonstrou um aspecto positivo do uso dos jogos, que apareceu também em outros momentos: o diálogo entre os alunos e os professores contribui para o entendimento dos conceitos envolvidos. Grando (2004) destaca a importância dos diálogos que ocorrem durante os jogos, em especial as diferentes formas de raciocínio. O mesmo ocorreu no próximo diálogo, construído pelo aluno $\mathrm{C} 8$, que realizou quatro pulos de tamanho 1 .

P: Quantos pulos você vai dar?

C8: Quatro.

P: E qual o tamanho do pulo?

C8: 1 .

O aluno pulou direto para o 4.

P: $O$ que o colega fez está certo?

Alguns: Não.

P: Está certo que você precisa chegar no 4 no final, mas são quatro pulos de tamanho 1. Vamos voltar.

C2: Primeiro, você pula no 1 e vai pulando de $1 \mathrm{em} 1$.

$\mathrm{O}$ aluno voltou e fez corretamente.

P: Entendeu, C8? Quantos pulos você deu?

C8: Quatro.

P: Qual o tamanho?

C8: 1 .

P: Você deu quatro pulos de 1. Como fica a conta?

C25: $4 \times 1$.

P: Exato.

Em seguida, C2 fez cinco pulos de tamanho 4.

$\mathrm{P}:$ Até que número você vai chegar?

C2: Se o pulo é de 4, primeiro, vou chegar no 4.

P: O primeiro pulo até o 4! Então, vai.

C2: O próximo, no 8.

C31: No 10.

P: Ela estava fazendo pulo de 4, então, mais 4, dá 8.

C2: O próximo é no 12.

$\mathrm{P}:$ E depois?

C2: 16.

P: Faltam quantos pulos?

C2: Um; vai cair no 20.

P: E aí, gente? Está certo? Ela fez os cinco pulos de 4?

Alguns: Sim!

P: Isso, ela fez! Como vocês vão registrar o cálculo?

C25: Mais ou vezes.

P: Se for mais, como é? 
C25: 10?

P: Vamos pensar!

P: Como você pensou para pular? Como você contou?

C2: De quatro em quatro.

P: Ela foi contando de quatro em quatro porque o pulo era de quatro. Quantas vezes você contou 4 ?

C2: Cinco.

P: Cinco vezes, ela contou o quatro. Então, quais contas nós podemos registrar?

C24: $4 \times 5$.

P: Ela deu quatro pulos de 5? Ou foram cinco pulos de 4?

C25: $5 \times 4$.

P: Isso, ela deu cinco pulos de 4. E qual outra conta poderíamos fazer? E se a gente for fazer uma soma? 5 x 4 é a mesma coisa que somar quantas vezes o 4 ?

C25: Como assim?

P: Ela fez 4, depois ela fez mais 4, depois mais 4, depois mais 4 e mais 4. Ela fez cinco vezes o 4 não é isso? Deu 20. Está certo. Se vocês fossem fazer uma conta de mais, vocês iriam somar quantas vezes o 4 ?

C25: Cinco.

P: Isso, vocês iriam fazer $4+4+4+4+4=20$ ou $5 \times 4$, que também é igual a 20 .

Novamente, surgiu a discussão sobre o tamanho do pulo e a quantidade de pulos. Para realizar a multiplicação, a ordem dos fatores não altera o resultado. Mas, como foram quatro pulos de tamanho 5, e não cinco pulos de tamanho 4, era importante que os alunos entendessem essa diferença. C31 foi o próximo a jogar. O aluno ficou pensativo para realizar dois pulos de comprimento 5. O diálogo seguiu com as mediações da professora, da mesma maneira que os anteriores, evidenciando a diferença entre dois pulos de 5 e cinco pulos de 2 .

Este exemplo que foi refletido e explorado pela professora-pesquisadora apresenta a distinção entre os termos da multiplicação. Embora a comutatividade indique que a ordem dos fatores não altera o produto, é a partir de situações-problemas que se pode identificar cada um dos termos da multiplicação. Nesse caso, número de pulos e tamanho dos pulos eram atributos diferentes.

Em seguida, foi a vez de C24, que fez dois pulos de comprimento 2.

P: São dois pulos de 2. [Com] o primeiro pulo, onde você tem que cair?

C24: No 2.

P: Isso, e depois? São dois pulos de 2; você, até agora, fez um.

C24: No 4 .

P: Qual conta você pode fazer para registrar?

P: Quantas vezes você pulou 2?

C24: Duas vezes.

P: Qual a distância?

C24: 4.

P: No total, foi 4, mas qual foi a distância de cada pulo?

C24: 2.

P: Então, como é? Quantas vezes você pulou o tamanho 2?

C24: Duas.

P: Então, você pulou duas vezes a distância de 2. Então, você fez $2 \times 2$, que dá?

C24: 4.

P: $2 \times 2$ é 4. E a metade de 4 é? 
C25: 2.

P: Para saber a metade, o que eu preciso fazer?

C24: É dividir ou de vezes.

C25: É dividido, né?

P: Isso, eu divido por 2.

A professora foi até a reta e se posicionou em cima do 2, perguntando.

P: Se dois é a metade de 4, vamos olhar: do quatro até o 2, tem quanto?

Alguns: 2.

P: E do zero até o 2, tem quanto?

Alguns: 2.

P: [A medida] é igual dos dois lados?

Alguns: Sim!

P: Tem 2: é a metade de 4. A metade é quando eu divido em duas partes iguais.

P: $2 \times 2$ é $4, e 4 \div 2$ é 2 .

Nesse diálogo, a professora-pesquisadora problematizou, mais uma vez, o termo metade para trabalhar o conceito de divisão envolvido no campo multiplicativo. Utilizou a reta para indicar a metade, divisão exata por 2, e o jogo possibilitou a visualização desse termo. Por meio da reta numérica, foi possível indicar que do 0 até o 2 a distância é 2 , e que do 2 até o 4 a distância também é 2. Dessa maneira, é mais fácil para o professor explicar e para os alunos compreenderem, do que levá-los a memorizar, sem compreensão, as operações inversas. A professora-pesquisadora percebeu que essa maneira é mais interessante para os alunos, do que ensiná-los a buscar o resultado da divisão exata na tabuada, de maneira mecânica.

Dessa forma, é possível o desenvolvimento do campo numérico na aprendizagem das crianças, ampliando o entendimento dos conceitos e das propriedades do SND, enquanto a professora-pesquisadora atesta seu desenvolvimento profissional a partir da reflexão sobre outras práticas pedagógicas.

C10 jogou, na sequência, e realizou cinco pulos de comprimento 3. Inicialmente, a aluna foi pulando sem respeitar o tamanho do pulo.

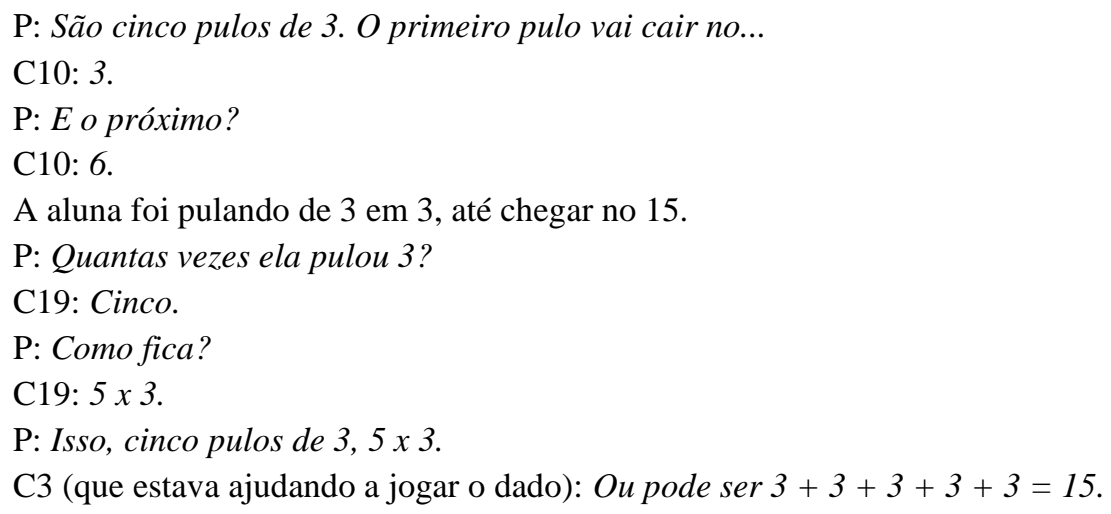

C3 fez a relação entre diferentes representações. Assim como 5 × $3=15$, também é possível fazer $3+3+3+3+3=15$. Logo depois, o C19 realizou cinco pulos de tamanho 2 , rapidamente, até chegar no 10, e depois voltou de 2 em 2, até chegar no zero.

P: Volta no 10. Você fez 5 x 2 e deu 10. E se eu pedir para você fazer $10 \div 2$, vai 


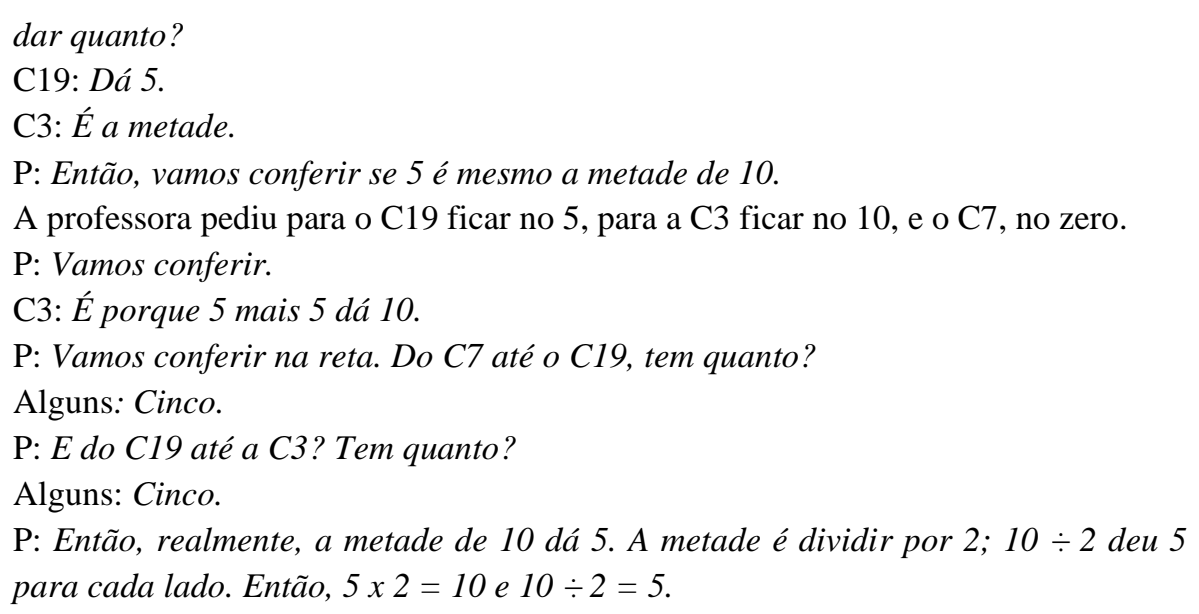

Esse diálogo contribuiu para a compreensão das ações da professora-pesquisadora sobre a multiplicação e sua inversa - a divisão -, o que colaborou para o trabalho com os jogos. Na fala "Pedi para o C19 ficar no 5, para a C3 ficar no 10, e o C7, no zero", é possível perceber que a professora se preocupou em explicar o conceito de metade, mostrando as quantidades iguais de cada lado da reta. Ela solicitou que os alunos ficassem em cima dos números para mostrar que, do zero ao 5 e do 5 ao 10 , o tamanho da reta é igual, e por isso estava ali, na reta, representada a metade do 10 , duas partes iguais.

\section{Considerações finais}

O artigo traz um recorte da investigação, apresentando a análise de alguns episódios do uso do jogo "A bota de muitas léguas". Ele contribuiu para que as crianças pudessem melhor compreender o campo multiplicativo, com ênfase na percepção da atribuição de significado para cada fator da multiplicação. As reflexões da professora-pesquisadora indicaram a importância do jogo como recurso viabilizador da exploração da multiplicação, em aspectos como o ensino do conceito de metade e dobro, quando duas variáveis estão envolvidas.

Mesmo provocando a compreensão da comutatividade, a professora-pesquisadora trouxe destaque para o fato de que, numa situação problema, cada fator tem um significado próprio. Refletir, mediar e apresentar novas situações a partir do vivido, colaborou para a aprendizagem dos alunos, mas também para o desenvolvimento profissional da professora, que foi aprimorando suas maneiras de ensinar, incorporando alguns recursos e produzindo outros, que promoveram o ensino de conceitos que tinha dificuldades para explicar.

A utilização da reta permitiu a visualização do termo metade, que, muitas vezes, é apenas transmitido a partir do uso de uma regra e meramente decorado pelos alunos, sem que seja plenamente compreendido. Os diálogos demonstraram que as mediações da professorapesquisadora no uso do jogo permitiram um processo de significação dos conceitos envolvidos.

A prática colaborou, ainda, para a compreensão do conceito de divisão, novo para boa parte dos alunos, pois a "conta de dividir" não tinha sido abordada naquela turma como o 
inverso da multiplicação. Proporcionou também o trabalho com conceitos já aprendidos, como a multiplicação dos números 1, 2, 3, 4 e 5, além de colaborar para o entendimento por aqueles que apresentavam dificuldades em matemática.

Após as jogadas, os alunos registraram os pulos em retas impressas, uma para cada criança. O registro do número de pulos na reta foi feito com facilidade. Porém, no registro do cálculo, alguns inverteram o multiplicando e o multiplicador, como ocorreu em algumas das jogadas, demonstrando que, para alguns, ainda é difícil compreender qual é o número que está sendo multiplicado, prevalecendo a comutatividade da multiplicação. Embora isso garanta o acerto no resultado, não afiança a compreensão da situação apresentada.

Esse processo levou a professora-pesquisadora a refletir que, talvez, isso ocorra por estar a prática escolar pautada, por vezes, mais na valorização da resposta correta do que no processo de entendimento da situação-problema apresentada. A resposta pode estar correta, mas isso não deveria ser o mais importante. $O$ aluno precisa compreender a situaçãoproblema, o que nos leva a refletir que a ordem dos fatores não altera o resultado, mas pode não assegurar o processo de entendimento, nem tampouco a compreensão da situaçãoproblema apresentada, que é o mais importante no processo de aprendizagem da matemática.

Afirmamos, a partir do exposto aqui, que a aprendizagem de matemática não deve se dar mediante o emprego de mecanizações, mas, sim, a partir de atividades que possam ser significativas para o aluno e promovam avanços no pensamento matemático, principalmente, nos anos iniciais, quando se estabelece o processo de alfabetização matemática. Portanto, enfatizar apenas as respostas corretas não é o caminho ideal para atribuir significado às atividades.

Cabe, ainda, destacar que o papel da professora-pesquisadora para constituir um ambiente propício a uma atividade é primordial, sobretudo, no que se refere a estimular a comunicação nas aulas de matemática, a respeitar e escutar os argumentos dos alunos. Promover a comunicação entre os alunos e a mediação entre o professor e as crianças é um caminho que objetiva compreender o pensamento matemático, sem limitar-se a enfatizar processos mecânicos que garantam respostas corretas. Tais afirmações foram vivenciadas no percurso da pesquisa.

As experiências vividas pela professora-pesquisadora permitiram-lhe desenvolver seus processos reflexivos, dar visibilidade ao que foi vivido em sala de aula, contribuindo de maneira significativa com a sua formação e também com outros professores de matemática dos anos iniciais. A pesquisa da própria prática emerge de situações reais, que foram e são vividas pelo professor pesquisador que explora alternativas, buscando constantemente aprimorar sua prática, a favor de ações pedagógicas que contribuam para a aprendizagem das crianças. 


\section{Referências}

BRASIL. Ministério da Educação. Diretoria de Apoio à Gestão Educacional. Pacto Nacional pela Alfabetização na Idade Certa: alfabetização matemática. Caderno de Jogos na Alfabetização Matemática. Brasília: MEC; SEB, 2014a.

BRASIL. Pacto Nacional pela Alfabetização na Idade Certa: alfabetização matemática. Caderno 3. Construção do Sistema de Numeração Decimal. Brasília: MEC; SEB, 2014b.

BRASIL. Pacto Nacional pela Alfabetização na Idade Certa: alfabetização matemática. Caderno de jogos na alfabetização matemática. Brasília: MEC; SEB, 2014c.

CEBOLA, Graça. Do número ao sentido do número. In: PONTE, J. P. et al. (org.). Actividades de investigação na aprendizagem da matemática e na formação de professores. Lisboa: SPCE-SEM, 2002. p. 223-239.

GRANDO, Regina Célia. O conhecimento matemático e o uso de jogo na sala de aula.

2000. 224 f. Tese (Doutorado em Educação) - Universidade Estadual de Campinas, Campinas, SP, 2000.

GRANDO, Regina Célia. O jogo e a matemática no contexto da sala de aula. 1. ed. São Paulo: Paulus, 2004.

GRANDO, Regina Célia. O jogo [e] suas possibilidades metodológicas no processo ensino-aprendizagem da matemática. 1995. 175 f. Dissertação (Mestrado em Educação) Universidade Estadual de Campinas, Campinas, SP, 1995.

LIMA, Claudia Neves do Monte Freitas de; NACARATO, Adair Mendes. A investigação da própria prática: mobilização e apropriação de saberes profissionais em Matemática.

Educação em Revista, Belo Horizonte, v. 25, n. 2, p. 241-266, ago. 2009.

https://doi.org/10.1590/S0102-46982009000200011.

MEGID, Maria Auxiliadora Bueno Andrade. As operações com números naturais. In: KLEINK, Mauricio Urban; MEGID NETO, Jorge (org.). Fundamentos da matemática, ciências e informática para anos iniciais do ensino fundamental. 1. ed. Campinas: FE/UNICAMP, 2010. p. 115-124.

MEGID, Maria Auxiliadora Bueno Andrade. Insubordinação criativa, consentida e esperada na formação de professores dos anos iniciais. In: D'AMBROSIO, Beatriz Silva; LOPES, Celi Espasandin (org.). Ousadia criativa nas práticas de educadores matemáticos. 1. ed. Campinas: Mercado de Letras, 2015. p. 21-41.

MUNIZ, Cristiano Alberto. Brincar e jogar: enlaces teóricos e metodológicos no campo da educação matemática. 2. ed. Belo Horizonte: Autêntica, 2014.

NACARATO, Adair Mendes; MENGALI, Brenda Leme da Silva; PASSOS, Cármen Lúcia Brancaglion. A matemática nos anos iniciais do ensino fundamental: tecendo fios de ensinar e do aprender. Belo Horizonte: Autêntica, 2009. 
NUNES, Terezinha et al. Educação Matemática: números e operações numéricas. 2. ed. São Paulo: Cortez, 2009.

PASSOS, Cármen Lúcia Brancaglion; NACARATO, Adair Mendes. Trajetória e perspectivas para o ensino de Matemática nos anos iniciais. Estudos Avançados, Ribeirão Preto, v. 32, n. 94, p. 119-135, 2018. https://doi.org/10.1590/s0103-40142018.3294.0010.

PONTE, João Pedro. Investigar a nossa própria prática. In: PONTE, João Pedro (org.).

Reflectir e investigar sobre a prática profissional. Lisboa: APM, 2002. p. 5-28.

SMOLE, Kátia Stocco; DINIZ, Maria Ignez; CÂNDIDO, Patrícia. Jogos de Matemática de $\mathbf{1}^{\mathbf{0}}$ ao $\mathbf{5}^{\circ}$ ano. Porto Alegre: Artmed, 2007.

TEIXEIRA, Paulo Marcelo Marini; MEGID NETO, Jorge. Uma proposta de tipologia para pesquisas de natureza interventiva. Ciências e Educação, Bauru, v. 23, n. 4, p. 1055-1076, 2017. https://doi.org/10.1590/1516-731320170040013.

TOLEDO, Marília; TOLEDO, Mauro. Teoria e prática de Matemática: como dois e dois. São Paulo: FTD, 2009.

VAN DE WALLE, John A. Matemática no ensino fundamental: formação de professores e aplicação em sala de aula. Tradução de Paulo Henrique Colonese. 6. ed. Porto Alegre: Artmed, 2009.

Checagem Antiplágio

Crossref

Similarity Check
Distribuído sobre

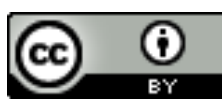

